\title{
Designing a conceptual syllabus for teaching metaphors and idioms in a foreign language context
}

\author{
Georgia Andreou and Loannis Galantomos \\ Department of Special Education \\ University of Thessaly
}

Received: 6 April 2007 / Accepted: 4 May 2007

ISSN: $1697-7467$

\begin{abstract}
In this paper we address the aspects that will determine the planning of a conceptual syllabus for teaching metaphors and idioms in a foreign language context. We argue that the theoretical background of the cognitive linguistic enterprise alters slightly the normal processes of developing learning materials. Hence, a series of preliminary and theoretical/practical concerns are introduced in order to answer the question of how a conceptual syllabus should look like.
\end{abstract}

Key words: conceptual syllabus, teaching metaphors, cognitive linguistics

RESUMEN: En este artículo abordamos los aspectos que deben tenerse en cuenta en la programación de un programa conceptual para la enseñanza de las metáforas en la lengua extranjera. Proponemos que el marco teórico de la lingüística cognitiva influye en cierta medida en los procesos normales de desarrollo de materiales de aprendizaje. Por tanto, presentamos una serie de cuestiones preliminares de carácter teórico-práctico, con el fin de dar respuesta a la cuestión de cómo debería ser un syllabus o programa conceptual.

Palabras clave: programa conceptual, la enseñanza de la metáfora, lingüística cognitiva.

\section{INTRODUCTION}

Traditionally metaphor was deemed to be a figure of speech, restricted to poetry and rhetorics and not a property of ordinary language. Furthermore, compared to literal meaning, it was taken to be a secondary and deviant means of expressing thoughts ${ }^{1}$. Respectively, idioms were labeled as dead metaphors (Fraser 1993: 330) and arbitrary structures, the meaning of which was not understandable from the individual words that made them up (Carter 1998: $65)$.

\footnotetext{
${ }^{1}$ For a synopsis of the major tenets of the traditional theory on metaphor see Lakoff and Johnson 1999:
} 119. 
These well established beliefs have been gradually falling out of favor since the publication of Lakoff's and Johnson's influential Metaphors we live by (1980). The two researchers made clear, by providing a high volume of empirical evidence, that metaphor is pervasive in our everyday thought, an intrinsic element of conventional language and moreover, it plays a central role in organization and functioning of the human conceptual system (Lakoff and Johnson 1980: 3). On the other hand, a significant part of idioms is taken to be partially compositional and motivated (Gibbs 1993a: 275), in that their occurrence in language can be traced back to certain cognitive mechanisms, namely metaphor, metonymy and conventional knowledge (Kövecses 2002: 201). Thus, the idiom 'burn up' in the sentence 'Her refusal to join my party burned me up' is a linguistic manifestation of the conceptual metaphor ANGER IS FIRE', the idiom 'get out of sth' in the sentence 'She managed to get out of his hand' is motivated by the conceptual metonymy THE HAND STANDS FOR CONTROL and finally the idiom "have sb's hands full' is explained by the common knowledge shared in a language community concerning the image and the fixed information about the function of human hand.

For many years, metaphor and subsequently idiom instruction were viewed as thorny issues by the vast majority of foreign language educators for a variety of reasons. Since metaphor was considered to be of trivial importance and a peripheral role was attributed to its existence in language, it was a natural consequence to receive little attention in a foreign language context. In the case of idioms, their meaning was taken to be arbitrary, unpredictable and an alternative way of expression given the existence of literal equivalents (Irujo 1993: 216-217). For example, instead of using the idiom 'spit fire' a student might have been encouraged to use the 'equivalent' 'get very angry/mad'. These beliefs influenced the teaching of this vocabulary strongly, with metaphors being neglected or marginalized and idioms being learned through alphabetical listings at a random order.

The cognitive linguistic approach to metaphors and idioms, from the early stages of its application in foreign language teaching, has been believed to facilitate learning and longterm retention of them (Kövecses 2002: 201). The major advantage of the cognitive linguistic methodology is that it reveals the hidden relationships that run among many metaphorical expressions and idioms. In other words, this vocabulary can be motivated by the existence of certain metaphors and/or metonymies. This fact, which is experimentally tested, throws light on the systematicity and the re-occurred conceptual metaphors that have an impact on the way we act, think and express our inner thoughts. That's why it can help second language learners (L2) categorize metaphorical linguistic expressions under certain conceptual domains and organize idioms according to the, above mentioned, cognitive mechanisms (Boers 1999: 54). Grouping, as a vocabulary learning strategy, is argued to have a beneficial effect on recalling words (Schmitt 1997: 213) and hence the cognitive linguistic approach can contribute, beyond any doubt, to this direction.

However, we should keep in mind that not all idioms are instances of conceptual metaphors/ metonymies. If we take the case of the idiom 'kick the bucket' this does not seem to be either a manifestation of a conceptual metaphor/metonymy or explained in terms of conventional knowledge shared by a language community.

${ }^{2}$ By convention metaphorical linguistic expressions are indicated in italics, whereas conceptual/metonymies are written in small capitals. 
As regards the arbitrariness of idioms and the claim that they have an alternative literal expression, psycholinguistic experiments showed that speakers do not believe that the meanings of an idiom and its literal counterpart are the same or similar (Gibbs 1993a: 272, 1993b: 7173). This conclusion leads us to the communicative functions of metaphor. Gibbs (1993a: 253, 1994: 124-125) argues that people can not avoid using metaphors in their ordinary speech because they conceptualize much of their abstract thought in terms of metaphor, metonymy and so on. Furthermore, he suggests that people via metaphor speak in a clear, compact and vivid way. In the words of Gibbs, 'figuration is not an escape from reality but constitutes the way we ordinarily understand ourselves and the world in which we live' (1994: 454).

Experimental evidence (e.g. Kövecses and Szabó 1996; Boers 2000a, 2000b) and theoretical contributions (e.g. Boers 1999, 2004; Lazar 1996; Littlemore 2001a) suggest that the cognitive linguistic framework can indeed assist L2 learners to acquire metaphors and idioms in an effective manner and achieve long-term retention in memory. More specifically, Kövecses and Szabó (1996) conducted an informal survey in order to measure the extent to which metaphoric awareness may aid foreign learners in learning idioms. This short-scaled experiment showed that L2 learners who were guided to employ the cognitive linguistic method performed $25 \%$ better compared to the students who were instructed to memorize the idioms in question (Kövecses 2002: 206). This evidence is quite encouraging because it gives new insights into teaching and learning metaphors and idioms in foreign language environments. In addition, this conclusion is of major significance since 'effective communication in a second language involves the ability to use [...] metaphors' (Littlemore 2001b). In fact, Danesi (1986: 9, 1992: 193) suggests that the true indication a learner has achieved mastery in a foreign language is his/her ability to metaphorize. Very few would argue against this claim which captures the essence of a well planned syllabus; figurative language should be at the heart of every learning material aimed at communicative proficiency.

Various suggestions have been made in literature regarding the teaching status of metaphor and idioms (e.g. Stahl 1999; Irujo 1986; Blachowicz and Fisher 1996; Bromley 1984). The common feature of these proposals is that metaphors and idioms should be taught in context. Moreover, they reproduce the traditional approaches according to which figurative language is a literature or poetry device and hence their teaching should start by exploiting these genres. To make metaphors and idioms memorable it is suggested that they should be taught in a separate way as if they were single, arbitrary words. It is clear that the above teaching ideas obscure the systematicity of figurative vocabulary in both language and thought and the conceptual relationship that lies among many metaphorical and idiomatic expressions.

It is our belief that learning metaphors and idioms in a more coherent way can be achieved by the development of a conceptual syllabus. A syllabus is not identical to a curriculum. In particular, 'a syllabus is a specification of the content of a course of instruction and lists what will be taught and tested' (Richards 2001: 2), whereas a curriculum is a more complex process with many components making it up, such as the performance of a needs analysis, the definition of goals and objectives and so on. Thus, a syllabus can be considered as an integral feature of a more detailed and comprehensive procedure (i.e. a curriculum).

In literature, many types of syllabuses have been identified but the most detailed proposal was made by Nunan (1988), who distinguished between two types, namely product-oriented and process-oriented syllabuses (ibid 1988: 27). These kinds of syllabuses come with certain 
subdivisions; product-oriented syllabuses can be either grammatical or functional-notional ones, whereas process-oriented syllabuses can be procedural, task-based or content based ones (Nunan 1988: 27-59). As O' Dell (1997: 260) remarks, product-oriented syllabuses lay an emphasis on what rather than how, that is the syllabus designer decides what the learners should learn; on the contrary, process-oriented syllabuses are concerned with how rather than what, that is the syllabus is developed according to L2 learners' real needs. In our case a conceptual syllabus can be said to belong to the product-oriented syllabuses category. According to Danesi (1995: 6-7), in a syllabus of this kind metaphors and idioms will be arranged around certain conceptual domains, while their instruction will put an additional emphasis on morphosyntactic and communicative cues.

The definition of a conceptual syllabus leads us to a related issue as regards the structure and the basic traits of it, in other words, what a conceptual syllabus should look like. This is the issue we are going to address in the section that follows, because syllabuses normally do not include much information about the necessary conditions in which they will be implemented (Rogers 1986: 209).

\section{Designing a conceptual Syllabus}

The second section will be divided into two parts. The first one will focus on more theoretical topics in respect of the intended outcomes (i.e. goals) of developing this type of learning material, the suitable age and the ideal L2 level of proficiency. In the second part, we will deal with more practical concerns regarding the structure and the content of a conceptual syllabus, namely what can be defined as an idiom for our purposes, the literalmetaphor distinction and finally we will discuss the kind of metaphors/metonymies that should be integrated into a metaphor-centered teaching programme.

In the beginning, we would like to indicate three requirements that should be met before conceptual-oriented activities take place.

Firstly, the existence of conceptual metaphors/metonymies in the mind is not a sufficient factor by itself for high performance in L2 acquisition. Thus, it is important for L2 learners to be sensitized about the pervasiveness of metaphor in language and the special aspects that constitute the cognitive linguistic approach before they are asked to apply it. In other words, it is suggested that they should be taught in an explicit and clear way how the cognitive linguistic strategy functions and its implications to foreign language learning (Kövecses 2001: 109; Kövecses and Szabó 1996: 351). Boers (1999) offers a very good source of metaphor awareness sample activities reflecting the conceptual technique.

Secondly, in a normal goals definition a teacher might be asked to develop material for communicative instances such as personal identification, filling in forms at public services and so on. On the contrary, we feel it is less likely for a teacher to come up with L2 learners' willingness to be taught the way native speakers of a certain language convey, say, their emotion of happiness. Since concepts and their linguistic manifestations are to the core of the cognitive linguistic enterprise it seems that we should take for granted their readiness to learn about abstract reasoning in L2.

Thirdly, it is essential to stress that a conceptual syllabus should be seen as a complementary means of metaphor and idiom instruction and not as the sole one (Boers 1999: 54-55). 
Despite the apparent advantages that accompany this strategy, we must admit that it fails to deal with idioms such as 'kick the bucket', that is it is applicable to a part of idioms and not to all of them. Thus, it should be considered as an additional technique for vocabulary enhancement.

Having clarified the three preliminary conditions that a teacher should bear in mind, we move on to some theoretical topics regarding the goals, the age and the suitable L2 learners' level of proficiency.

In particular, the first stage, when learning materials are designed, is to define the goals that are expected to be brought about. In literature, three basic kinds of goals are mentioned, namely overall, specific and immediate goals (objectives) (Rogers 1986: 146-148). The overall goal of every learning programme is communicative competence and communication in general. Communicative competence is defined as 'everything that a speaker needs to know in order to communicate appropriately within a particular community' (Saville-Troike 2006: 134). Although several models of communicative competence have been proposed, the most influential was developed by Bachman (1990: 81-110). This consists of three elements, language competence, strategic competence and psychological mechanisms (ibid 1990: 84).

Specific goals refer to shorter-terms goals, which in our case is the development of L2 learners' conceptual fluency (Danesi 1995: 5) or metaphorical/metaphoric competence (e.g. Danesi 1992: 190; Littlemore and Low 2006b: 79). Littlemore (2001a: 461) suggests that four components make up metaphoric competence, namely the original character of metaphor production, mastery of metaphor comprehension, ability to figure out the meaning of a metaphor and speed in doing so. In other words, this term is related to L2 learners' ability to interpret and produce metaphors (Littlemore and Low 2006b: 79). Metaphoric competence is considered to be an essential component of communicative competence (Danesi 1986: 3; Littlemore and Low 2006a: 269). In Bachman's model, the ability to interpret figurative language is under sociolinguistic competence but as Littlemore and Low (2006b) showed exhaustively that metaphoric competence is an intrinsic aspect of all aspects of competencies included in Bachman's theoretical framework. Thus, figurative instruction arises as an indispensable feature of all skills an L2 learner needs to master in order to acquire a high level of foreign language proficiency.

In order to do so, it is essential to break down the specific goal (i.e. metaphoric competence) into separate and manageable units, that is to plan everyday learning activities in order to enhance figurative lexis acquisition in one abstract domain each time. Thus, the objective of a daily class could be to teach metaphors and idioms that native speakers of the language, in question, use to express, lets say, their emotion of fear or the concept of progress.

As regards the issue of age, it seems that adults are more susceptible to successful application of the cognitive linguistic framework. This aptness derives from the focus of the method, in question, on abstract reasoning, its linguistic manifestation and the way human conceptual system is structured. Adults have analytic ability, learning capacity and pragmatic skills compared to younger L2 learners, who are not analytical, have usually fewer inhibition and documented brain plasticity (Saville-Troike 2006: 82). In the same vein, Spolsky (1989) cited in Cook (2001: 135) points out that sophisticated understanding and reasoning require older students, whereas children are more open to L2 instruction in informal settings. Therefore, older foreign students seem to have an advantage over children in this domain. 
With respect to the suitable students' level of proficiency, Boers (2004: 221-222) suggests that intermediate learners should be more susceptible to the cognitive linguistic strategy. Beginners will face problems due to lack of the lexical knowledge required to understand the given instructions. On the other hand, advanced learners may hesitate and be dubious producing figurative lexis, whose acceptability in L2 is questionable.

In the paragraphs to follow we will draw our attention to more practical issues concerning the definition of an idiom, the literal-metaphor distinction and finally the kinds of metaphors/ metonymies included in a conceptual syllabus.

The first topic to be concerned with is the ambiguity attributed to the term idiom, which subsequently brings to light the thorny matter of its definition. It is commonly agreed that idioms lack a sufficient definition, which in turn frustrates both teachers and learners (Grant and Bauer 2004: 38). Several criteria have been suggested and even more classifications have been proposed. These typologies rely on semantic, lexical, syntactic, functional, and lexicographical approaches respectively (Moon 1998: 9-18). This disagreement led Gibbs (1994: 269-270) to adopt a more liberal and flexible view and label as idioms structures such as sayings, proverbs, phrasal verbs, tournure idioms, binomials and so on. Instead of sticking to one of the above theoretical models it is suggested that a conceptual syllabus should contain idioms, which beyond any doubt appear to be linguistic expressions of conceptual metaphors/metonymies, that is imageable idioms (Lakoff 1987: 447) or metaphorical idioms (Lakoff and Johnson 1999: 67) or more general figurative idioms (Boers 2001: 35). This category of idioms comes with conventional mental images and knowledge about the nature of this image (Lakoff 1987: 447; Lakoff and Johnson 1999: 68). Thus, it is more convenient to accept a solution of this kind. Experimental evidence (e.g. Boers 2001; Boers and Demecheleer 2001) suggests that teaching figurative idioms facilitates in depth learning and retention of them. In addition to this arrangement, idioms that are not motivated by conceptual metaphors/ metonymies can be provided in order to enrich the content of a conceptual syllabus. For instance, idioms such as 'shoot the breeze', which seem unrelated to any conceptual domain, can be embedded in the additional vocabulary for the concept of argument, indicating at the same time its register (informal), the national variety of English (US) and any constraints that may apply on its internal structure.

The second matter has to do with the literal-metaphor distinction. Traditionally, literal meaning was taken to be a uniformed term, which can be used in an unproblematical way to contrast with the peripheral figurative meaning (Gibbs 1994: 76). Despite this well established view, Lakoff (1986: 292) showed that literality encodes at least four different meanings, namely conventional literality, subject matter literality, nonmetaphorical literality and truthconditional literality, whereas Gibbs (1993a: 257, 1994: 75) added one more type, namely context-free literality. These five different meanings of literality call for a clarification in order to ensure a unified notion of literality and avoid further misunderstandings. Thus, Lakoff (1986: 293) identifies nonmetaphorical literality as the type of literal meaning opposed to metaphorical/figurative one. In other words, "concepts that are not comprehended via conceptual metaphor might be called "literal" (Lakoff 1993: 205). The pedagogical implications of this clarification are to structure a conceptual syllabus around two sections, a literal (with its new content) and a metaphorical one.

The third topic regards the metaphors/metonymies listed in a conceptual syllabus, that is what conceptual domains a teacher should include. An implicit contribution related to this 
issue is found in Kövecses $(2002,2005)$ where the notions of universal and culture-specific metaphors are introduced. Kövecses (2005: 35) suggests the universal existence of some types of conceptual metaphors is based on human physiology (i.e. embodied experience). These potentially universal metaphors include such cases as the emotions, the time, the self, and the event structure metaphor (Kövecses 2005: 64). Kövecses came to this conclusion by looking at a wide range of metaphorical linguistic examples from typologically different (i.e. genetically unrelated) languages such as English, Chinese, Hungarian, Japanese and so on. Moreover, other metaphors are thought to be culture-specific, that is different ethnic groups will elaborate certain conceptual domains in a different way. The pedagogical application of this argument is to arrange a conceptual syllabus around universal and culture-specific metaphors/ metonymies. To find out which metaphors are culture-specific we are planning to carry out a study in which we will list a number of concepts and ask native speakers of a certain culture to evaluate their importance in their lives. This task presupposes that we take for granted the universal character of the above mentioned metaphors. Upon the completion of this survey and after the statistical analysis, native speakers will be asked to write a short essay in which they will express their thoughts about the most important concepts. This way we will form a list of culture-specific metaphors/metonymies.

Needless to mention that a conceptual syllabus should contain morphosyntactic information about the included lexis, along with the ideal register of metaphors and idioms in question, and authentic language. These are not trivial points because when Littlemore and Low (2006b) dealt with the manner figurative language is presented in the published English conceptual textbooks they came up with artificial language and lack of transformational and context cues (ibid 207).

We believe that a conceptual syllabus with the above traits and structure will offer L2 learners new insights into discovering alternative ways in learning figurative language. Both empirical and experimental data suggest that organizing metaphors and idioms according to their underlying conceptual domains and raising students' awareness of such a systematicity can enhance L2 figurative instruction.

\section{Conclusions}

To sum up, in this article we addressed the aspects that should be taken into consideration when a conceptual syllabus is about to be designed.

In the first section, we showed that figurative language is not peripheral and of trivial importance but rather it is ubiquitous in everyday, conventional language. This pervasiveness of metaphors and idioms relates figurative language to high levels of L2 proficiency/fluency.

In the second section we looked at the suggested steps taken to design a conceptual syllabus. We introduced some preliminary conditions that should be taken into consideration before L2 students engage in the conceptual -oriented material. Then we specified the general settings for applying a conceptual syllabus, namely the expected goals, the age factor, and suitable students' level of proficiency in L2 and we moved on with more practical matters as regards the definition of an idiom, the problematic literal-metaphor distinction and finally the types of metaphors/metonymies embedded in the structure of a syllabus of this kind. 
Our aim was to suggest how a conceptual syllabus should be like and what are the possible constraints upon its application in L2 classrooms. Teaching figurative language will always be a stumbling block for both teachers and students and for this reason we tried to provide a few pointers on how to organize and teach metaphors and idioms effectively in a foreign language context within the framework of cognitive linguistics.

\section{REFERENCES}

Bachman, L. (1990). Fundamental Considerations in Language Testing. Oxford: Oxford University Press.

Boers, F. (1999). 'Learning vocabulary through metaphoric awareness.' Études et Travaux 3: 5365.

Boers, F. (2000a). 'Metaphor awareness and vocabulary retention.' Applied Linguistics 21/4: 553571.

Boers, F. (2000b). 'Enhancing metaphoric awareness in specialized reading.' English for Specific Purposes 19: 137-147.

Boers, F. (2001). 'Remembering figurative idioms by hypothesizing about their origin.' Prospect 16/3: 35-43.

Boers, F. (2004). 'Expanding Learners' Vocabulary Through Metaphor Awareness: What Expansion, What Learners, What Vocabulary?' in Achard, M. and Niemeierand, S. (eds): Cognitive Linguistics, Second Language Acquisition, and Foreign Language Teaching. Berlin \& New York: Mouton de Gruyter.

Boers, F. and Demecheleer, M. (2001). 'Measuring the impact of cross-cultural differences on learners' comprehension of imageable idioms.' ELT Journal 55/3: 255-262.

Blachowicz, C. and Fisher, P.J. (1996). Teaching vocabulary in all classrooms. New Jersey: Merrill Prentice Hall.

Bromley, K.D. (1984). 'Teaching idioms.' The Reading Teacher 38: 272-276.

Carter, R. (1998). Vocabulary. Applied Linguistics perspectives. London \& New York: Routledge. Cook, V. (2001). Second Language Learning and LanguageTeaching. London: Arnold.

Danesi, M. (1986). 'The Role of Metaphor in Second Language Pedagogy.' Rassegna Italiana di Linguistica Applicata 18/3: 1-10.

Danesi, M. (1992). 'Metaphor and Classroom Second Language Learning. 'Romance Language Annual 3: 189-194.

Danesi, M. (1995). 'Learning and teaching languages: The role of 'conceptual fluency'.' International Journal of Applied Linguistics 5/1: 3-20.

Fraser, B. (1993). 'The interpretation of novel metaphors' in Ortony, A. (ed.).

Gibbs, R. Jr. (1993a). 'Process and products in making sense of tropes' in Ortony, A. (ed.).

Gibbs, R. Jr. (1993b). 'Why Idioms Are Not Dead Metaphors' in Cacciari, Cr. and Tabossi, P. (eds): Idioms: Processing, structure, and interpretation. Hillsdale, NJ: Lawrence Erlbaum.

Gibbs, R. Jr. (1994). The Poetics of Mind. Cambridge: Cambridge University Press.

Grant, L. and Bauer, L. (2004). 'Criteria for Re-defining Idioms: Are we Barking up the Wrong Tree?' Applied Linguistics 25/1: 38-61.

Irujo, S. (1986). 'A piece of cake: Learning and teaching idioms.' ELT Journal 40/3: 236-242.

Irujo, S. (1993). 'Steering clear: Avoidance in the production of idioms.' IRAL 31/3: 205-219.

Kövecses, Z. (2001).' A cognitive linguistic view of learning idioms in an FLT context' in Pütz, 
M., Niemeier, S. and Dirven, R. (eds): Applied Cognitive Linguistics. Language Pedagogy, vol. 2. Berlin \& New York: Mouton de Gruyter.

Kövecses, Z. (2002). Metaphor. A Practical Introduction. Oxford: Oxford University Press.

Kövecses, Z. (2005). Metaphor in Culture. Universality and Variation. Cambridge: Cambridge University Press.

Kövecses, Z. and Szabó, P. (1996). 'Idioms: A view from cognitive semantics.' Applied Linguistics 17/3: 326-355.

Lakoff, G. (1986). 'The Meanings of Literal.' Metaphor and Symbolic Activity 1/4: 291-296.

Lakoff, G. (1987). Women, Fire, and Dangerous Things: What Categories Reveal about the Mind. Chicago \& London: The University of Chicago Press.

Lakoff, G. (1993). 'The contemporary theory of metaphor' in Ortony, A. (ed.).

Lakoff, G. and Johnson, M. (1980). Metaphors we Live By. Chicago and London: The University of Chicago Press.

Lakoff, G. and Johnson, M. (1999). Philosophy in the Flesh. The Embodied Mind and its Challenge to Western Thought. New York: Basic Books.

Lazar, G. (1996). 'Using figurative language to expand students' vocabulary.' ELT Journal 50/1: 43-51.

Littlemore, J. (2001a). 'Metaphoric Competence: A Language Learning Strength of Students With a Holistic Cognitive Style?' TESOL Quarterly 35/3: 459-491.

Littlemore, J. (2001b). 'Metaphoric intelligence and foreign language learning.' Humanising Language Teaching 3/2. http:/ www .hltmag.co.uk/ mar01 /mart1. htm.

Littlemore, J. and Low, G. (2006a). 'Metaphoric Competence, Second Language Learning, and Communicative Language Ability.' Applied Linguistics 27/2: 268-294.

Littlemore, J. and Low, G. (2006b). Figurative Thinking and Foreign Language Learning. New York: Palgrave McMillan.

Moon, R. (1998). Fixed Expressions and Idioms in English. A Corpus-Based Approach. Oxford: Oxford University Press.

Nunan, D. (1988). Syllabus Design. Oxford: Oxford University Press.

O’ Dell, F. (1997). 'Incorporating vocabulary into syllabus' in Schmitt, N. and McCarthy, M. (eds).

Ortony, A. (ed.). (1993). Metaphor and Thought. Cambridge: Cambridge University Press.

Richards, J.C. (2001). Curriculum Development in Language Teaching. Cambridge: Cambridge University Press.

Rogers, A. (1986). Teaching Adults. Berkshire: Open University Press.

Saville-Troike, M. (2006). Introducing Second Language Acquisition. Cambridge: Cambridge University Press.

Schmitt, N. (1997). 'Vocabulary learning strategies' in Schmitt, N. and McCarthy, M. (eds).

Schmitt, N. and McCarthy, M. (1997). Vocabulary, Description, Acquisition and Pedagogy. Cambridge: Cambridge University Press.

Spolsky, B. (1989). Conditions for Second Language Learning. Oxford: Oxford University Press.

Stahl, S.A. (1999). Vocabulary Development. Brookline, MA: Brookline Books. 